\title{
Neglected clubfoot treated by serial casting: a narrative review on how possibility takes over disability
}

\author{
Cristina Alves ${ }^{1}$, Anna Ey Batlle ${ }^{2,3}$, Marta Vinyals Rodriguez ${ }^{3}$ \\ ${ }^{1}$ Serviço de Ortopedia Pediátrica do Hospital Pediátrico - CHUC, EPE, Coimbra, Portugal; ${ }^{2}$ Hospital Sant Joan de Déu, Barcelona, Spain; ${ }^{3}$ Equipo \\ Internacional Ortopedia Pediatrica Dra Ey, Barcelona, Spain \\ Contributions: (I) Conception and design: C Alves; (II) Administrative support: C Alves; (III) Provision of study materials or patients: All authors; \\ (IV) Collection and assembly of data: All authors; (V) Data analysis and interpretation: All authors; (VI) Manuscript writing: All authors; (VII) Final \\ approval of manuscript: All authors. \\ Correspondence to: Cristina Alves, MD, MSc, FEBOT. Serviço de Ortopedia Pediátrica do Hospital Pediátrico - CHUC, EPE, Avenida Afonso \\ Romão, 3000-602 Coimbra, Portugal. Email: cristina.alves@me.com.
}

\begin{abstract}
The Ponseti Method is recognized as the best treatment for congenital idiopathic clubfoot in newborns and its principles became also adopted for treating older children with neglected deformity. This review aims to evaluate the role and effectiveness of serial casting in the treatment of neglected clubfoot, worldwide. Clubfoot is a complex tridimensional congenital foot deformity that can be easily treated after birth by correct manipulation of the foot and serial casting, with a great majority of cases requiring a percutaneous Achilles tenotomy, which can be organized as an ambulatory day procedure, without need for general anesthesia. However, in many low-income countries, treatment is not readily available, and many children grow up with disabling foot deformities. When compared to a newborn's clubfoot, a neglected clubfoot is different and more challenging to treat, as bones become ossified while malaligned and exposed to abnormal forces. Application of the Ponseti method in children with untreated idiopathic clubfoot older than walking age leads to satisfactory outcomes, has a low cost, and avoids surgical procedures likely to cause complications. The upper age limit for the use of Ponseti Method in clubfoot treatment is yet to be established. Success of clubfoot treatment is mostly defined as a pain-free, aesthetically acceptable plantigrade foot, with no need for extensive surgical tissue release after casting and tenotomy. The results of the Ponseti method for the treatment of clubfoot in children after the walking age are encouraging, with more than $80 \%$ of success in achieving initial correction and $18-62.5 \%$ of relapses. If Ponseti casting is not successful, any further interventions should be carefully selected and planned, in order to maintain the length of the foot and avoid intracapsular scarring or bony fusions.
\end{abstract}

Keywords: Neglected clubfoot; walking age; serial casting; Ponseti

Submitted Jan 06, 2021. Accepted for publication Jun 04, 2021.

doi: 10.21037/atm-21-65

View this article at: https://dx.doi.org/10.21037/atm-21-65

\section{Introduction}

Clubfoot is a complex tridimensional deformity involving the hindfoot, midfoot, and forefoot. Time is the fourth dimension to the condition, as flexible deformities become fixed and more difficult to manage, as patients get older. Time changes the nature of the deformity and eventual prognosis (1).

Children with clubfoot may present after the walking age, especially in low-income and middle-income countries, where $\sim 80 \%$ of children with clubfoot are born. As there are scarce medical resources, treatment is often delayed or inadequate (2).

Neglected clubfoot may be defined as untreated cavusadductus-varus-equinus foot in otherwise normal older children, adolescents or adults (3). For treatment purposes it has been considered that neglected clubfoot is one which 


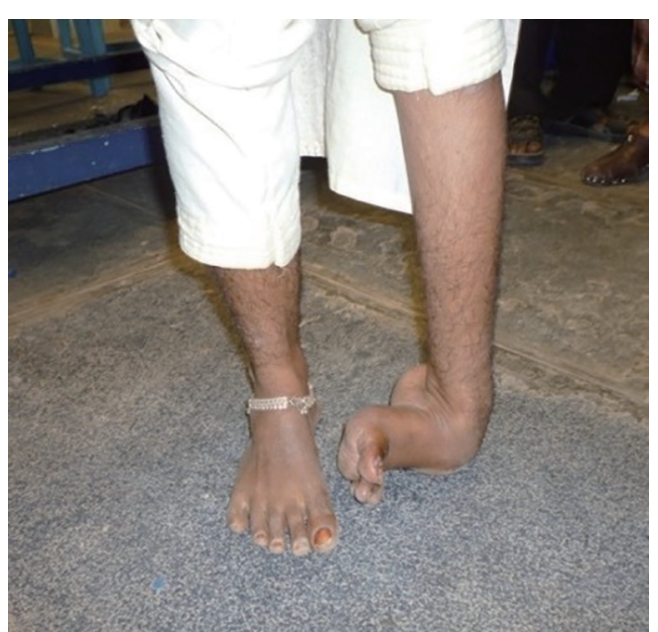

Figure 1 Left 'neglected' clubfoot in a 22 years old woman. The foot is grossly deformed and has painful callosities.

has not been treated until after the age when treatment is expected to produce a successful deformity correction. However, there is no universal definition, reason for which an obviously neglected clubfoot to one practitioner may be seen just as a more challenging foot to another (4).

One must beware that there is a social implication inherent to the term 'neglected'. This definition varies within different cultural contexts and expectancies of when a child should have treatment to avoid developmental delays, ambulation difficulties, and shoe-wear problems (4). Shah et al. highlight that 'Neglect' has a negative connotation, as it implies indifference or carelessness, which is often not true in low-income countries with poor healthcare facilities, where parents have difficulties in finding and getting early and appropriate treatment. They suggest that the terminology 'walking age clubfoot' would be more appropriate, as it is nonjudgemental, reflects the reality and more accurately defines the problem in developing countries (2). However, the term 'neglected clubfoot' is well established in the literature and among practitioners, describing the situation of walking age children who did not receive treatment, without specifically blaming anyone or anything.

As most children start walking between 12 and 18 months of age, it is reasonable to assume that it would be ideal for all children to receive adequate clubfoot treatment before completing 1 year of age. Therefore, we define a 'neglected clubfoot' as any clubfoot which has not received any treatment before the age of 1 year.

When compared to a newborn's clubfoot, a neglected clubfoot is different and more challenging to treat. The neglected clubfoot is stiffer, as capsular tissues have hypertrophied with growth and weight-bearing $(3,5)$. While tarsal bones in infants are largely composed of cartilage, and correction of a clubfoot at this age occurs in part through morphologic changes of the cartilaginous bones that respond to Ponseti manipulation and casting $(6,7)$, as the child gets older bones are further matured and correction through morphologic changes of the cartilaginous anlages cannot be expected as much as shown for infant clubfeet $(4,8)$. Furthermore, weight bearing may prompt to the appearance of skin callosities and mild bony hypertrophy at sites of impact, with hypoplasia of understressed structures (Figure 1). There is also an adjustment of the abnormally positioned muscles and tendons to the longstanding deformity: the abductor hallucis muscle becomes a powerful force maintaining forefoot supination and cavus; tibialis anterior tendon becomes strong and hypertrophied, whereas its antagonists, the peronei muscles, are weak and overstretched (4). Development of a normal osseous anatomy in a child's foot depends on transmission of force through congruent and anatomically aligned articulations. In untreated, or inadequately treated, clubfoot, bones become ossified while malaligned and exposed to abnormal forces, which adds up to the already abnormal clubfoot anatomy (1).

Neglected clubfoot is still a significant public health problem in many countries and brings many challenges to healthcare professionals who come into the care of these patients. While a number of surgical techniques (soft tissue releases, arthrodesis) have been used to correct clubfoot in different ages, various complications were observed, namely soft tissues contractures, neurovascular complications, infections, and limb length discrepancy. Currently, the nonoperative management (manipulation, serial casting, and braces) of clubfoot is considered as the best choice and it is widely accepted. This narrative review aims to describe what is known about serial casting in the treatment of neglected clubfoot and evaluate its worldwide role and effectiveness. We present the following article in accordance with the Narrative Review reporting checklist (available at http://dx.doi.org/10.21037/atm-21-65).

\section{Methods}

We present a narrative overview of the literature focused on serial casting as a method of treatment for neglected clubfeet. We included all types of research studies, both 
experimental and observational, published in English, French, Portuguese and Spanish. The information was obtained from the following resources:

* MEDLINE database, search 1921-January 2021. Keywords: Clubfoot, Neglected; Clubfoot, Older Children.

* $\quad$ Embase $^{\circledR}$ database, search 1947-January 2021. Keywords: Clubfoot, Neglected; Clubfoot, Older Children. LILACS database, search 1979 January 2021. Key words: Clubfoot, Neglected; Clubfoot, Older Children.

* Hand searches of the references of retrieved literature and authoritative texts.

* Personal and Hospital libraries searching for texts on clubfoot.

* Discussions with experts in the field of clubfoot.

* Personal experience.

\section{Results}

We found 14 observational studies reporting the application of Ponseti Method in children with neglected clubfeet. The main findings of these studies are summarized in Table 1 .

\section{Discussion}

When treating patients with neglected clubfeet, the goals remain similar as for newborns: to achieve a normal looking, plantigrade, flexible and pain-free foot, not requiring shoe modifications and with the least chance to relapse (6). A recent systematic review, including 46 studies reporting on the results of children treated for clubfoot with Ponseti method, highlighted that relapses have been reported to occur up to the age of 10 years, but very few studies follow patients for more than 8 years. The authors also found that relapse rate and number of feet requiring joint-sparing surgeries increased with the duration of follow-up, therefore stating that more long-term follow-up studies are needed in order to accurately predict the risk of relapse. Parents and patients should be informed about the possibility of relapse during middle and late childhood. Follow-up until skeletal maturity should be assured (9).

Although surgery has been advocated for patients presenting with clubfeet after walking age, surgery does not prevent recurrence and reoperations are frequently required, with a consequent increase in complications and limitations in functional outcomes $(10,11)$.

\section{What Are the goals of treatment of neglected clubfeet?}

Application of the Ponseti method in children with untreated idiopathic clubfoot older than walking age leads to satisfactory outcomes, has a low cost, and avoids surgical procedures likely to cause complications (12). It must be kept in mind that when treating neglected clubfeet, plantigrade is a more achievable goal than flexibility, as the neglected clubfoot is usually stiff when treatment is started (4).

It is important to keep in mind that the goals of patients should be taken into consideration. Patients with neglected untreated clubfoot, may have no complains of pain or functional impairment (13).

\section{Success of Ponseti treatment protocols for neglected clubfeet}

Ponseti method became standardized as the treatment for clubfoot, worldwide. However, neglected clubfoot is a difficult problem, for which the technique was not initially devised. Although Ponseti did not express an upper age limit for successful application of his technique, he only reported its use on babies whose treatment was initiated before 6 months of age (14-18). Nevertheless, subsequent studies have documented that the Ponseti method can be used to correct an initially untreated or even a post-surgical recurrent clubfoot, after the age of 12 months (19-31) (Table 1).

Although untreated severe clubfoot is rarely found in developed countries, there are many children in low-andmid-income countries who do not have access to any kind of treatment. It has been estimated that $50 \%$ of children worldwide with clubfeet receive no treatment. These children and adolescents are unable to wear normal shoes and have functional problems, as their untreated feet are grossly deformed, often have painful callosities in the foot areas where they weight-bear, as they walk with fixed severe equinus of the ankle, varus/inversion of the hindfoot, midfoot adduction and forefoot pronation (1) (Figure 1).

Some authors claim that the success of treatment is inversely proportional to the age at the time of treatment, but still support that the first line of treatment should be a course of casting independent of the severity and age. A metanalysis showed that the rate of initial success for Ponseti technique in children over 3 years old is $87.41 \%$ (95\% CI, 0.7341-0.9458) and 88.84\% (95\% CI, $0.7885-$ 0.9445 ) for children under 3 years old. This metanalysis did not find any linear association between the final outcome and the mean age of patients (12).

Treatment of neglected clubfeet should be started with 


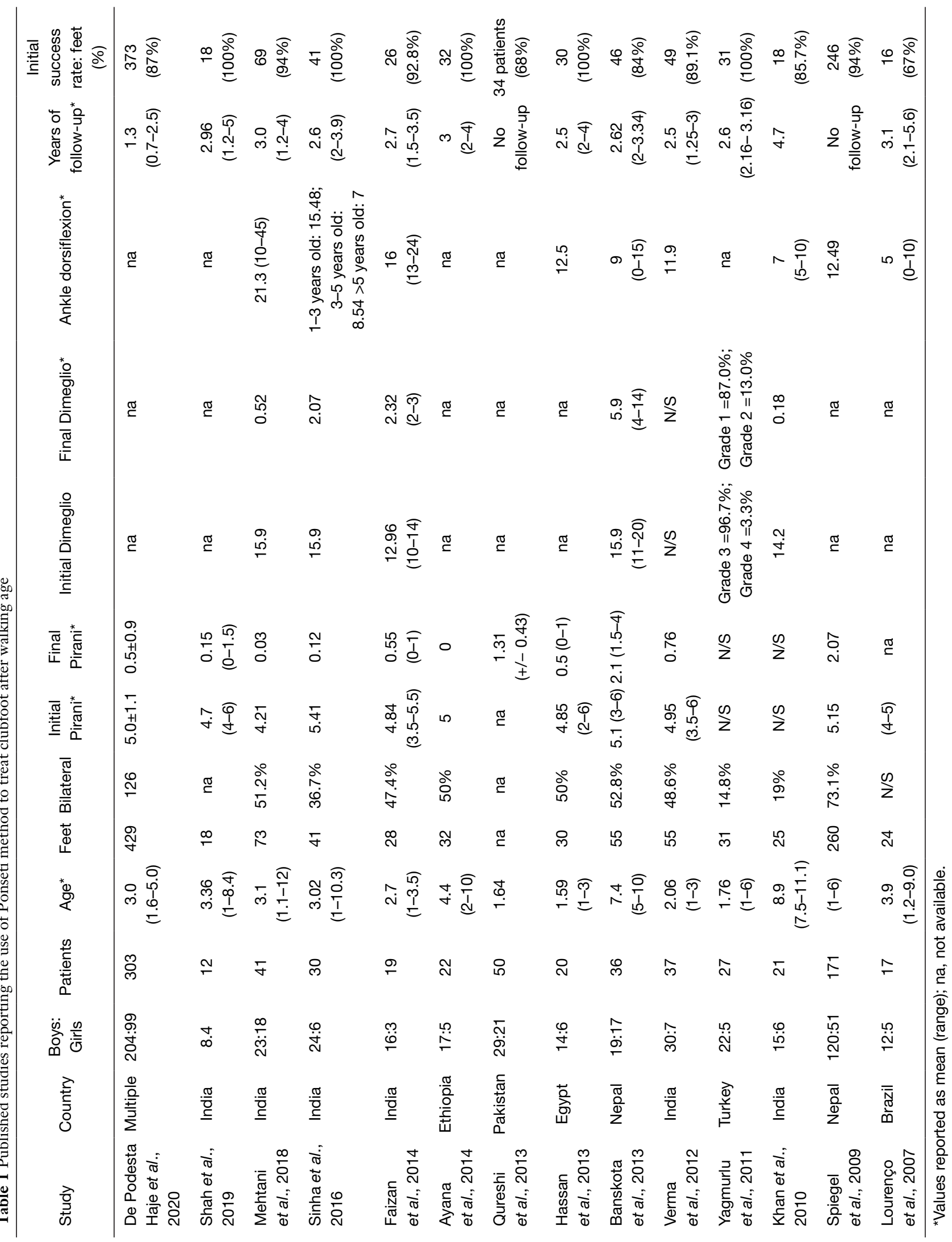


a Ponseti protocol, as many of these previously untouched feet can be or become supple. Some patients will still need an operative intervention, ranging from tendon lengthening and/or tendon transfers to other options, but the Ponseti method of serial casting is a valid treatment for nearly all neglected clubfeet, except perhaps for those with bony synostoses (3).

In 260 neglected clubfeet of Nepalese children, age ranging from 1 to 6 years, only 37 (14\%) required soft tissue releases (21). The age of patients at the onset of treatment did not influence the number of casts needed or the ability to correct the feet.

In another study, including 24 Brazilian patients with neglected clubfeet, age range 1.2-9.0 years, mean follow-up 3.1 years, equinus recurrence required surgical correction in 15 patients, 7 of whom were treated with a repeat Achilles tenotomy, 8 with a posterior release; 16 of the 24 patients were rated as a good result (19).

Khan and Kumar prospectively studied children over 7 years of age with neglected clubfeet, reporting on 25 feet with at least 4 years' follow-up; 19 feet did well, with good flexibility at follow-up. Six feet (24\%) relapsed, requiring posteromedial releases (20).

In a multicentre retrospective study, de Podesta Haje et al. reported on the results obtained with Ponseti method when treating 429 clubfeet in 303 patients with no previous treatment and older than one-year, from 15 centers in 7 countries. The median age at beginning of treatment was three years, and the median follow-up 1.3 years. After a mean of 6.8 casts, $87 \%$ (373 of 429) of neglected clubfeet were corrected. Residual equinus was treated with percutaneous Achilles tenotomy in $83 \%$ of clubfeet. A bilateral foot abduction brace was prescribed and used in $70 \%$ of children. Relapses occurred in 31\% (32 of 103) of clubfeet and were associated with age less than 4 years at treatment onset, and bracing noncompliance (31).

A difficult challenge is the treatment of relapses after previous posteromedial releases. It has been shown that serial casting plays an important role in the treatment of these patients. Nogueira and colleagues corrected 83 clubfeet after relapses resulting from previous posteromedial releases (32). The age range was 7 months to 14 years. At an average follow-up of 45 months, 71 feet were plantigrade. One patient, who was later shown to have a subtalar synostosis, had no correction of his hindfoot varus after 10 casts. Of the 12 relapses, only 6 required surgery (tibialis anterior tendon transfer) and 3 of those also required lateral column shortening, plantar fasciotomy, and Achilles tendon lengthening. No relationship was found between outcomes and age at treatment.

The tibialis anterior should be carefully assessed prior to surgery, because it is often the cause of relapses and has a high likelihood of potentiating yet another recurrence. A transfer of the tibialis anterior, after correction has been attained, can help prevent the problems inherent to an imbalanced foot (3).

Around 7\% of children treated with Ponseti casting for neglected clubfoot will experience complications, with most common being erythema, superficial abrasions, swelling and osteopenia (12).

\section{Specificities when applying Ponseti method after walking age}

There are variations among different authors applying the Ponseti method to patients after walking age. The manipulation is done using the lateral aspect of the talar head as fulcrum and the inferomedial aspect of the first metatarsal, bringing the foot gradually into abduction and it is worth to spend 2-5 minutes in manipulating the foot. One may use the thenar eminence of the hand to make the fulcrum on the talar head, and thus increase the efficiency of the manipulation and possibly decrease the risk of possible skin irritations.

The application of casts in patients with neglected clubfeet must be very detailed, concentrating attention on the head of the talus, the first metatarsal and the plantar fascia, so that the correcting forces are well distributed pressure and a uniform molding is achieved, thus avoiding pressure sores (33).

Most practitioners report the use of above-knee casts (Figure 2) and perform cast changes with 5-7 days intervals in between $(21,23,24,26,28,29)$. However, some authors reported cast changes every 2 weeks $(19,25,27)$.

The cast is usually performed using plaster of Paris, but reinforcement with fiberglass as an outside layer, whenever possible, avoids breaking of the cast in these older children (2).

The number of casts needed to achieve correction of the clubfoot ranges between 4 and 12 (12).

In the setting of treatment of neglected clubfeet, tenotomy is often performed under local anesthesia and patients will have three weeks cast after tenotomy, with duration of casting ranging between 3 and 6 weeks (12). In the last cast, it is usual possible to achieve $40-50^{\circ}$ of foot abduction, less than the $70^{\circ}$ of abduction recommended for newborns $(2,19,23,34)$. 


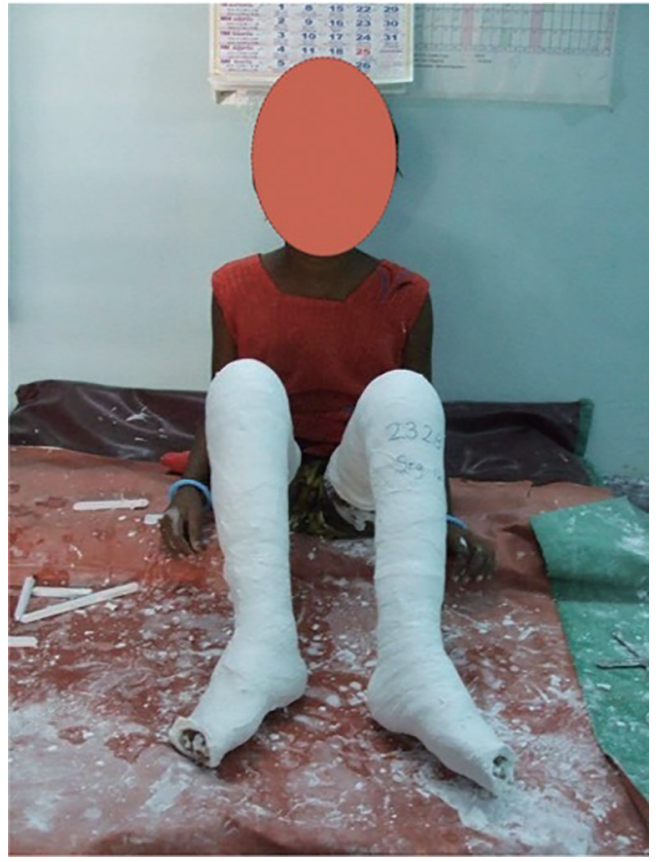

Figure 2 Above knee Ponseti casting in an 11 years old girl with bilateral clubfoot.

Mehtani et al. modified the Ponseti method for treating neglected clubfeet: 2 weeks after tenotomy, they change the cast to a below-knee, weight-bearing cast in maximum achievable dorsiflexion and abduction. In addition, they switched removal of the post-tenotomy cast (22). They believe that this strategy grants a better final ankle dorsiflexion, which might be a relevant achievement when patients live in environments in which squatting is of cultural and social importance.

\section{The relapse problem}

In children with neglected clubfeet, treated after the walking age, the estimated relapse rate ranges from $18 \%$ to $62.5 \%(12,19,31)$. Most studies report short follow-ups, reason for which there is a need of intermediate and longterm studies to understand all the factors associated with relapse in neglected clubfoot.

de Podesta Haje et al. found that patients younger than four years at the treatment onset and abduction brace noncompliance have a higher rate of relapses. Possibly, the potential for foot growth in younger patients may be a predisposing factor for relapses (31).

Non-adherence to the use of orthosis protocol following clubfoot correction is recognized as an important risk factor for recurrence in children that are treated before walking age, with the use of boots-and-bars being considered crucial in order to avoid recurrence of the deformity $(16,35,36)$. However, there are circumstances in which bracing is not available (31). Furthermore, there are no consensual recommendations or bracing protocol for older children treated for neglected clubfeet. An abduction orthosis, in which 2 shoes are attached to a bar, in $50^{\circ}$ external rotation and shoulders distance between them, is the most frequent type of brace used after the end of correction. There are wide variations in the recommendations for its use and the duration of the protocols ranges between 3 and 12 months after tenotomy (12). Full-time bracing for $23 \mathrm{~h} /$ day for the initial 3 months seems impractical in these older children. Adopting directly a nights-and-naps protocol with the foot abduction brace, seems easier (2). Some authors reported using an AFO (Ankle-Foot Orthosis) $(19,25,27)$.

The first sign of relapse in a neglected clubfoot treated by Ponseti method is loss of dorsiflexion and recasting is still an option considered by some authors (12). According to Khan et al., recurrences in children with neglected clubfeet are due to ligament thickening, retraction of the tibialis posterior tendon, and low adherence to orthosis use after serial cast changes and Achilles tenotomy (20).

Tibialis anterior tendon transfer to the lateral cuneiform in children older than 3 years of age, may be considered as part of the initial treatment protocol, as it might act as an internal brace and prevent recurrences $(2,33)$. However, tibialis anterior transfer is not universally used by all authors and one must be aware that this surgery needs operative room resources and expertise, which may not be available in the environments where children with neglected clubfeet are most often treated.

There are no scores validated to evaluate the results of treatment of neglected clubfeet. Most authors have used Pirani (37) and Diméglio (38) scores to assess the initial deformity and outcome after the end of treatment.

Success of clubfoot treatment is mostly defined as a pain-free, aesthetically acceptable plantigrade foot, with no need for extensive surgical tissue release after casting and tenotomy (12) (Figure 3).

\section{Conclusions}

The upper age limit for the use of Ponseti method in clubfoot treatment is yet to be established. The results of the Ponseti method for the initial treatment of clubfoot 

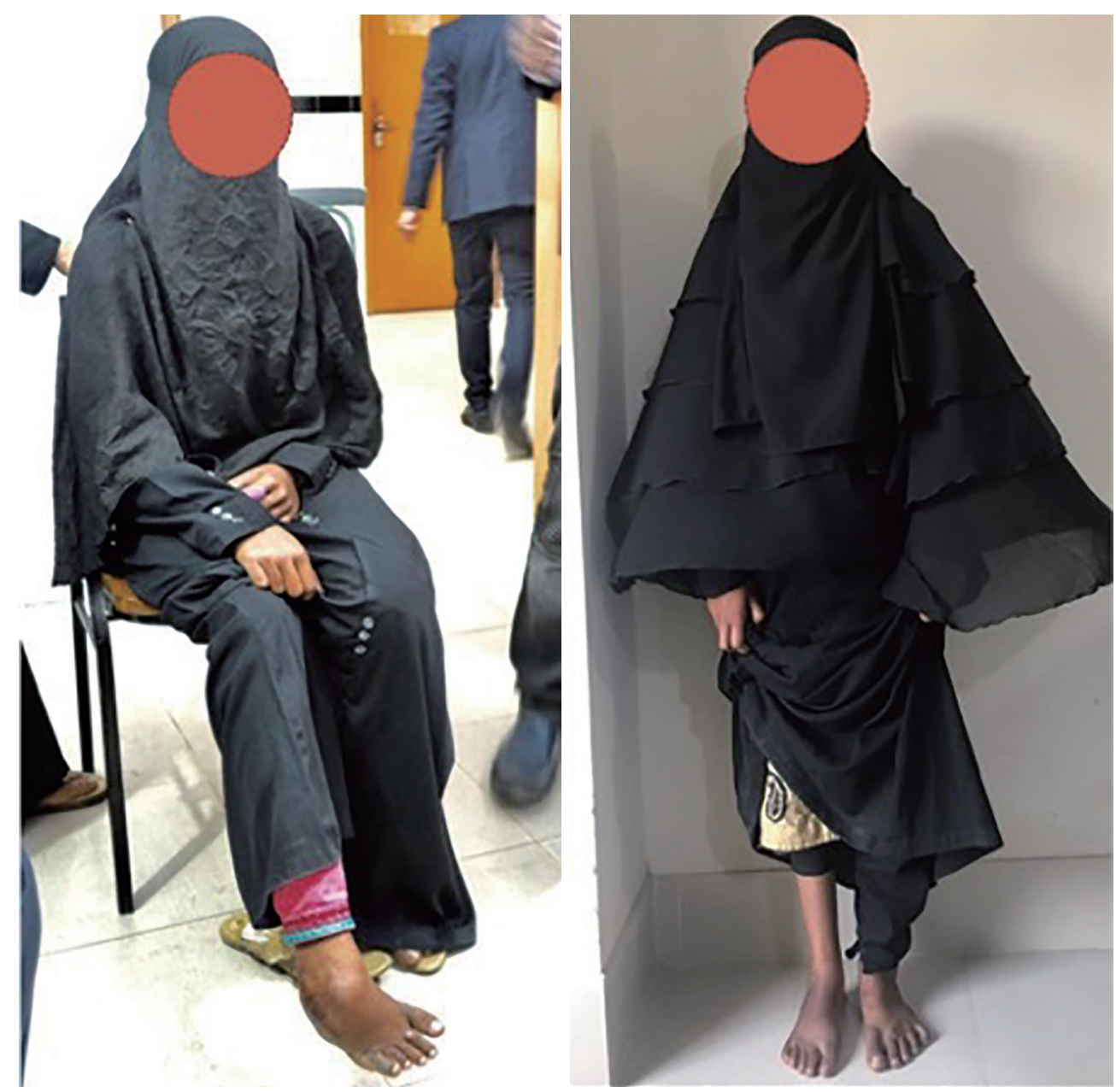

Figure 3 A 16 years old girl with neglected clubfoot treated with Ponseti Method.

in children after the walking age are encouraging, with more than $85 \%$ of initial success in achieving aesthetically acceptable, functional, and pain-free plantigrade feet. If Ponseti casting is not successful, any further interventions should be carefully selected and planned, in order to maintain the length of the foot and avoid intracapsular scarring or bony fusions.

\section{Acknowledgments}

Funding: None.

\section{Footnote}

Provenance and Peer Review: This article was commissioned by the Guest Editors (Federico Canavese and Alain
Dimeglio) for the series "Clubfoot" published in Annals of Translational Medicine. The article has undergone external peer review.

Reporting Checklist: The authors have completed the Narrative Review reporting checklist. Available at https:// dx.doi.org/10.21037/atm-21-65

Peer Review File: Available at https://dx.doi.org/10.21037/ atm-21-65

Conflicts of Interest: All authors have completed the ICMJE uniform disclosure form (available at https://dx.doi. org/10.21037/atm-21-65). The series "Clubfoot" was commissioned by the editorial office without any funding or sponsorship. CA is a Councillor of the European Paediatric 
Orthpaedic Society (EPOS) and a Member of the Medical Advisory Board of the Ponseti International Association (PIA). The other authors have no conflicts of interest to declare.

Ethical Statement: The authors are accountable for all aspects of the work in ensuring that questions related to the accuracy or integrity of any part of the work are appropriately investigated and resolved.

Open Access Statement: This is an Open Access article distributed in accordance with the Creative Commons Attribution-NonCommercial-NoDerivs 4.0 International License (CC BY-NC-ND 4.0), which permits the noncommercial replication and distribution of the article with the strict proviso that no changes or edits are made and the original work is properly cited (including links to both the formal publication through the relevant DOI and the license). See: https://creativecommons.org/licenses/by-nc-nd/4.0/.

\section{References}

1. Peterson N, Prior C. Correction of the Neglected Clubfoot in the Adolescent and Adult Patient. Foot Ankle Clin 2020;25:205-20.

2. Shah A, Mehta R, Aroojis A. The Ponseti method of clubfoot treatment in walking age children: is it effective? A study of 56 children from 1 to 10 years of age. J Pediatr Orthop B 2019;28:159-66.

3. Eidelman M, Kotlarsky P, Herzenberg JE. Treatment of relapsed, residual and neglected clubfoot: adjunctive surgery. J Child Orthop 2019;13:293-303.

4. van Bosse HJ. Treatment of the neglected and relapsed clubfoot. Clin Podiatr Med Surg 2013;30:513-30.

5. Penny JN. The neglected clubfoot. Tech Orthop 2005;20:153-66.

6. Ponseti IV. Congenital clubfoot: fundamentals of treatment. New York: Oxford University Press Inc, 1996.

7. Pirani S, Zeznik L, Hodges D. Magnetic resonance imaging study of the congen- ital clubfoot treated with the Ponseti method. J Pediatr Orthop 2001;21:719-26.

8. Nogueira MP, Amaral DT. How much remodeling is possible in a clubfoot treatment? Magnetic reso- nance imaging study in a 7-year-old child. J Limb Lengthen Reconstr 2018;4:49-54.

9. Thomas HM, Sangiorgio SN, Ebramzadeh E, et al. Relapse Rates in Patients with Clubfoot Treated Using the Ponseti Method Increase with Time: A Systematic Review.
JBJS Rev 2019;7:e6.

10. Ettl V, Kirschner S, Krauspe R, et al. Midterm results following revision surgery in clubfeet. Int Orthop 2009;33:515-20.

11. Mehrafshan M, Rampal V, Seringe R, et al. Recurrent club-foot deformity following previous soft-tissue release: mid-term outcome after revision surgery. J Bone Joint Surg Br 2009;91:949-54.

12. Ferreira GF, Stéfani KC, Haje DP, et al. The Ponseti method in children with clubfoot after walking age Systematic review and metanalysis of observational studies. PLoS One 2018;13:e207153.

13. Salinas G, Chotigavanichaya C, Otsuka NY. A 30 year functional follow-up of a neglected congenital clubfoot in an adult: a case report. Foot Ankle Int 2000;21:1037-9.

14. Ponseti IV, Smoley EN. Congenital club foot: the results of treatment. J Bone Joint Surg Am 1963;45:261-75, 344.

15. Laaveg SJ, Ponseti IV. Long-term results of treatment of congenital club foot. J Bone Joint Surg Am 1980;62:23-31.

16. Morcuende JA, Dolan LA, Dietz FR, et al. Radical reduction in the rate of exten- sive corrective surgery for clubfoot using the Ponseti method. Pediatrics 2004;113:376-80.

17. Cooper DM, Dietz FR. Treatment of idiopathic clubfoot. A thirty-year follow-up note. J Bone Joint Surg Am 1995;77:1477-89.

18. Ponseti IV. Treatment of congenital club foot. J Bone Joint Surg Am 1992;74:448-54.

19. Lourenço AF, Morcuende JA. Correction of neglected idiopathic club foot by the Ponseti method. J Bone Joint Surg Br 2007;89:378-81.

20. Khan SA, Kumar A. Ponseti's manipulation in neglected clubfoot in children more than 7 years of age: a prospective evaluation of 25 feet with long-term follow-up. J Pediatr Orthop B 2010;19:385-9.

21. Spiegel DA, Shrestha OP, Sitoula P, et al. Ponseti method for untreated idio- pathic clubfeet in Nepalese patients from 1 to 6 years of age. Clin Orthop Relat Res 2009;467:1164-70.

22. Mehtani A, Prakash J, Vijay V, et al. Modified Ponseti technique for management of neglected clubfeet. J Pediatr Orthop B 2018;27:61-6.

23. Sinha A, Mehtani A, Sud A, et al. Evaluation of Ponseti method in neglected clubfoot. Indian J Orthop 2016;50:529-35.

24. Faizan M, Jilani LZ, Abbas M, et al. Management of idiopathic clubfoot by Ponseti technique in children presenting after one year of age. J Foot Ankle Surg 
2015;54:967-72.

25. Ayana B, Klungsoyr PJ. Good results after Ponseti treatment for neglected congenital clubfoot in Ethiopia. A prospective study of 22 children (32 feet) from 2 to 10 years of age. Acta Orthop 2014;85:641-5.

26. Qureshi AR, Warriach SB. Evaluation of Ponseti method for management of idiopathic clubfoot in toddlers. Pak J Med Sci 2013;7:730-2.

27. Hassan MK, Ibrahim AH, Mostafa MM, et al. Ponseti method for management of neglected idio- pathic clubfoot. Curr Orthop Pract 2013;24:295-7.

28. Banskota B, Banskota AK, Regmi R, et al. The Ponseti method in the treatment of children with idiopathic clubfoot presenting between five and ten years of age. Bone Joint J 2013;95-B:1721-5.

29. Verma A, Mehtani A, Sural S, et al. Management of idiopathic clubfoot in toddlers by Ponseti's method. J Pediatr Orthop B 2012;21:79-84.

30. Yagmurlu MF, Ermis MN, Akdeniz HE, et al. Ponseti management of clubfoot after walking age. Pediatr Int 2011;53:85-9.

31. de Podesta Haje D, Maranho DA, Ferreira GF, et al. Ponseti Method After Walking Age - A MultiCentric Study of 429 Feet: Results, Possible Treatment Modifications and Outcomes According to Age Groups. Iowa Orthop J 2020;40:1-12.

Cite this article as: Alves C, Batlle AE, Rodriguez MV. Neglected clubfoot treated by serial casting: a narrative review on how possibility takes over disability. Ann Transl Med 2021;9(13):1103. doi: 10.21037/atm-21-65
32. Nogueira MP, Ey Batlle AM, Alves CG. Is it possible to treat recurrent clubfoot with the Ponseti technique after posteromedial release?: a preliminary study. Clin Orthop Relat Res 2009;467:1298-305.

33. Ortiz-Montoya DF, Posada A, Quesada-Aguilar MP, et al. Pie equino varo congénito no tratado en el paciente escolar, adolescente y adulto. Revisión de conceptos actuales. Revista Colombiana de Ortopedia y Traumatología 2021;35:54-61.

34. Bashi RH, Baghdadi T, Shirazi MR, et al. Modified Ponseti method of treatment for correction of neglected clubfoot in older children and adolescents--a preliminary report. J Pediatr Orthop B 2016;25:99-103.

35. Haft GF, Walker CG, Crawford HA. Early clubfoot recurrence after use of the Ponseti method in a New Zealand population. J Bone Joint Surg Am 2007;89:487-93.

36. Dobbs MB, Rudzki JR, Purcell DB, et al. Factors predictive of outcome after use of the Ponseti method for the treatment of idiopathic clubfeet. J Bone Joint Surg Am 2004;86:22-7.

37. Pirani S, Outerbridge H, Sawatzky B, et al. A reliable method of clinically evaluating a virgin clubfoot evaluation. 21st SICOT Congress. 1999.

38. Diméglio A, Bensahel H, Souchet $\mathrm{P}$, et al. Classification of clubfoot. J Pediatr Orthop B 1995;4:129-36. 